tive IgA deficiency, in genetically susceptible individuals, is a phenomenon common to agents possessing properties which modify rheumatoid disease.

We thank Dr D D Felix-Davies, Dr C F Hawkins, and Dr B McConkey for permission to study their patients.

We (JDP and MF) are in receipt of grants from the Arthritis and Rheumatism Council.

1 Stanworth DR, Johns P, Williamson N, Shadforth M, Felix-Davies DD, Thompson R. Drug induced IgA deficiency in rheumatoid arthritis. Lancet $1977 ; \mathrm{i}: 1001-2$.

2 Johns P, Felix-Davies DD, Hawkins CF, et al. IgA deficiency in patients with rheumatoid arthritis treated with D-penicillamine or gold. Ann Rheum Dis 1978;37:289.

${ }^{3}$ McConkey B, Amos RS, Durham S, Forster PJ, Hubball S, Walsh L. Sulphasalazine in rheumatoid arthritis. $\mathrm{Br} M e d$ F 1980;i:442-4.

${ }^{4}$ Hjalmarson $\mathrm{O}$, Hanson LA, Nilsson LA. IgA deficiency during Dpenicillamine treatment. $\mathrm{Br}$ Med F 1977; i:549.

5 Seager J, Jamison DL, Wilson J, Hayward AR, Soothill JP. IgA deficiency, epilepsy and phenytoin treatment. Lancet 1975;ii :632-5.

(Accepted 25 February 1983)

Rheumatology Unit, Queen Elizabeth Hospital, Birmingham B15 2TJ

J P DELAMERE, MB, MRCP, honorary senior registrar

M FARR, MB, clinical research fellow

Department of Medicine, Dudley Road Hospital, Birmingham

K A GRINDULIS, MB, MRCP, registrar

Correspondence to: Dr J P Delamere.

\section{Pressurised aerosol with conical spacer is an effective alternative to nebuliser in chronic stable asthma}

Aerosol treatment delivered by a $750 \mathrm{ml}$ conical spacer attached to a pressurised aerosol (Nebuhaler, Astra Pharmaceuticals Ltd) is as effective as a simple nebuliser in acute severe asthma. ${ }^{1}$ This may be due to improved deposition of the drug in the lungs because a dense, slowly moving cloud of small drug particles is produced and inhaled in a relatively large volume, over several breaths if necessary, through a one way valve. ${ }^{2}$ Intermittent positive pressure breathing is widely used for severe asthma and may be marginally superior to simple nebuliser treatment. ${ }^{3}$ The relative value of these techniques has not been established in chronic stable asthma, although nebulisers are often used in preference to pressurised aerosols. We have therefore compared the bronchodilator responses of nine patients with chronic stable asthma to the beta ${ }_{2}$ stimulant terbutaline administered in cumulative doubling doses by pressurised aerosol fitted with a conical spacer, Acorn nebuliser, and Bennett intermittent positive pressure breathing equipment.

\section{Patients, methods, and results}

We studied nine patients aged between 24 and 56 years with atopic asthma. All required regular bronchodilator treatment and none had needed a change in treatment for three months. Each patient gave informed consen and was studied at the same time of day on three separate days within one week. Sodium cromoglycate and bronchodilators were discontinued for at least 12 hours before the tests. On each occasion we asked the patients to inhale cumulative doubling doses of terbutaline $(0 \cdot 5+1 \cdot 0+2 \cdot 0+4 \cdot 0 \mathrm{mg})$ at
30 minute intervals using each of the three techniques in random order. To determine the magnitude and site of drug action we measured forced expiratory volume in one second ( $\mathrm{FEV}_{1}$ ), forced vital capacity (FVC), and maximal expiratory flow at $30 \% \mathrm{FVC}\left(\mathrm{V}_{30}\right)$ as an indicator of peripheral airway calibre. ${ }^{4}$ We made measurements at 10 minute intervals throughout the studies and used the best of three measurements in analysis. A paired $t$ test was used to compare the mean values obtained at each dose with each technique.

There was no significant difference in baseline $\mathrm{FEV}_{1}, \mathrm{FVC}$, or $\mathrm{V}_{30}$ on each study day. The table shows the mean expiratory flow rates for each technique at cumulative doses of terbutaline. For both $\mathrm{FEV}_{1}$ and FVC there were no statistically significant differences in the responses at any dose. At cumulative doses of 1.5 and $3.5 \mathrm{mg}$ terbutaline the conical spacer produced a mean $\nabla_{30}$ which was similar to that from the intermittent positive pressure breathing device and significantly greater than that from the nebuliser $(p<0 \cdot 05)$.

\section{Comment}

In these patients the conical spacer was as effective as the intermittent positive pressure breathing device and nebuliser in delivering an aerosol bronchodilator throughout the therapeutic dose range. In dosages higher than those conventionally used from pressurised aerosols, but often used from nebulisers, the conical spacer was significantly more effective than the nebuliser in improving flow rates at low lung volumes. These results support the theory that the technique enhances peripheral airway drug deposition and bronchodilatation by allowing evaporation of droplets of propellant and production of drug particles of smaller size which are inhaled in a large volume. ${ }^{25}$ There was no significant difference between the intermittent positive pressure breathing device and nebuliser at any dosage, although there was a trend in $\mathrm{V}_{30}$ in favour of the former at higher doses. The conical spacer is more than 50 times cheaper than the least expensive nebuliser equipment. The device also removes the risk of failure to coordinate aerosol activation with inspiration, which is a frequent problem in bronchodilator administration.

We conclude that the use of a conical spacer with a pressurised aerosol is a simple, cheap, and effective alternative to a nebuliser or intermittent positive pressure breathing device for bronchodilator treatment in moderately severe chronic stable asthma and is therefore likely to be of great value for domiciliary use.

We thank Astra Pharmaceuticals Limited for supplies of the Nebuhale conical spacer and terbutaline.

${ }^{1}$ Morgan MDL, Singh BV, Frame $\mathrm{MH}$ et al. Terbutaline aerosol given through pear spacer in acute severe asthma. Br Med $\mathcal{F} 1982 ; 285: 849-50$.

2 Newman SP, Moran F, Pavia D et al. Deposition of pressurized suspension aerosols inhaled through extension devices. Am Rev Respir Dis $1981 ; 124$ 317-20.

3 Webber BA, Shenfield GM, Paterson JW. A comparison of three differen techniques for giving nebulized albuterol to asthmatic patients. $A m$ Rev Respir Dis 1974;109:293-4.

- Mead J, Turner JM, Macklem PT, et al. Significance of relationship between lung recoil and maximum expiratory flow. F Appl Physiol 1967 $22: 95-108$.

5 Pavia D, Thomson ML, Clarke SW, et al. Effect of lung function and mode of inhalation on penetration of aerosol into human lung. Thorax 1977 32:194-7.

(Accepted 3 March 1983)

Department of Respiratory Medicine, City Hospital, Edinburgh EH10 5SD

J F O'REILLY, MA, MRCP, medical registrar

D R BUCHANAN, MB, MRCP, medical registrar

M F SUDLOW, MB, MRCP, consultant physician

Correspondence to: Dr J F O'Reilly, Department of Respiratory Medicine Bristol Royal Infirmary, Bristol BS2 8HW.

Mean $( \pm S E M)$ changes in maximum expiratory flow rates after cumulative terbutaline inhalation by three techniques

\begin{tabular}{|c|c|c|c|c|c|c|c|c|c|}
\hline \multirow{2}{*}{$\begin{array}{l}\text { Cumulative } \\
\text { terbutaline } \\
\text { dosage (mg) }\end{array}$} & \multicolumn{3}{|c|}{$\mathrm{FEV}_{\mathbf{1}}(\mathrm{l})$} & \multicolumn{3}{|c|}{ FVC (1) } & \multicolumn{3}{|c|}{$\mathrm{V}_{\mathrm{so}}(1 / \mathrm{s})$} \\
\hline & $\begin{array}{c}\text { Aerosol and } \\
\text { spacer }\end{array}$ & Nebuliser & IPPB & $\begin{array}{c}\text { Aerosol and } \\
\text { spacer }\end{array}$ & Nebuliser & IPPB & $\begin{array}{c}\text { Aerosol and } \\
\text { spacer }\end{array}$ & Nebuliser & IPPB \\
\hline $\begin{array}{l}\text { Baseline } \\
0.5 \\
1.5 \\
3.5 \\
7.5\end{array}$ & $\begin{array}{l:l}2.39 & 0.37 \\
2.67 & 0.38 \\
2.82 & 0.40 \\
2.80 & 0.42 \\
2.85 & 0.41\end{array}$ & $\begin{array}{l}2.36+0.38 \\
2.68+0.37 \\
2 \cdot 74+0.37 \\
2 \cdot 86+0.40 \\
2.90 \div 0.40\end{array}$ & $\begin{array}{l:l}2.25 & 0.34 \\
2.60 & 0.37 \\
2.72 & 0.38 \\
2.82 & 0.38 \\
2.85 & 0.37\end{array}$ & 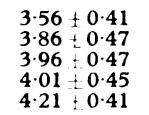 & $\begin{array}{ll:}\mathbf{3} \cdot 68 & 0.38 \\
\mathbf{4} \cdot 05 & 0.41 \\
\mathbf{4} \cdot 22 & 0.41 \\
\mathbf{4} \cdot \mathbf{3 4} & \mathbf{0 . 4 3} \\
\mathbf{4} \cdot 29 & \mathbf{0 . 4 6}\end{array}$ & $\begin{array}{l:l}3.53 & 0.33 \\
3.88 & 0.39 \\
4.05 & 0.37 \\
4.25 & 0.37 \\
4 \cdot 19 & 0.37\end{array}$ & 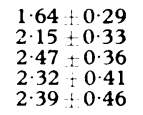 & $\begin{array}{l:l}1.54 & 0.32 \\
2.13 & 0.34 \\
1.93 & 0.38 \\
1.89 & 0.35 \\
2.00 & 0.31\end{array}$ & $\begin{array}{l:l}1.71 & 0.33 \\
2.03 & 0.40 \\
2.33 & 0.50 \\
2.42 & 0.53 \\
2.32 & 0.50\end{array}$ \\
\hline
\end{tabular}

